\title{
LA-UR-18-29843
}

Approved for public release; distribution is unlimited.

Title: Materials Aware Hydrodynamics

Author(s): $\quad$ Hull, Lawrence Mark

Intended for: $\quad$ Fellows Induction

Issued: 
Disclaimer:

Los Alamos National Laboratory, an affirmative action/equal opportunity employer, is operated by the Los Alamos National Security, LLC for the National Nuclear Security Administration of the U.S. Department of Energy under contract DE-AC52-06NA25396. By approving this article, the publisher recognizes that the U.S. Government retains nonexclusive, royalty-free license to publish or reproduce the published form of this contribution, or to allow others to do so, for U.S. Government purposes. Los Alamos National Laboratory requests that the publisher identify this article as work performed under the auspices of the U.S. Department of Energy. Los Alamos National Laboratory strongly supports academic freedom and a researcher's right to publish; as an institution, however, the Laboratory does not endorse the viewpoint of a publication or guarantee its technical correctness. 


\section{Materials Aware Hydrodynamics}

2018 Fellows Induction Ceremony

Study Center

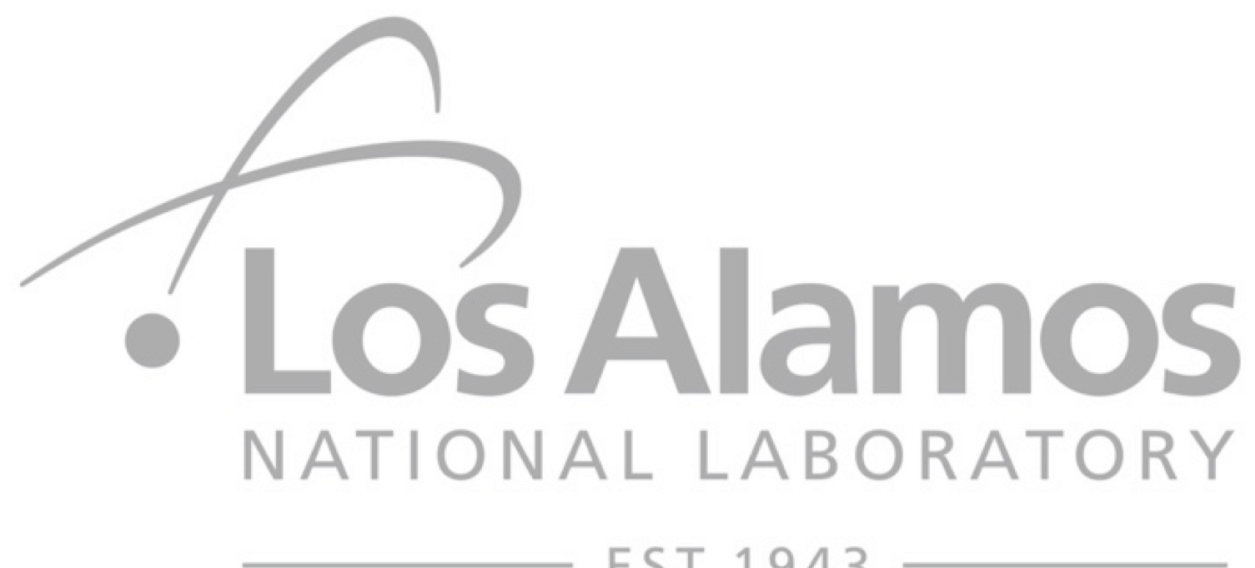

Lawrence M. Hull, J-3, Focused Experiments, Integrated Weapons Experiments Division 22 October 2018 


\section{Hydrodynamics - water dynamics}
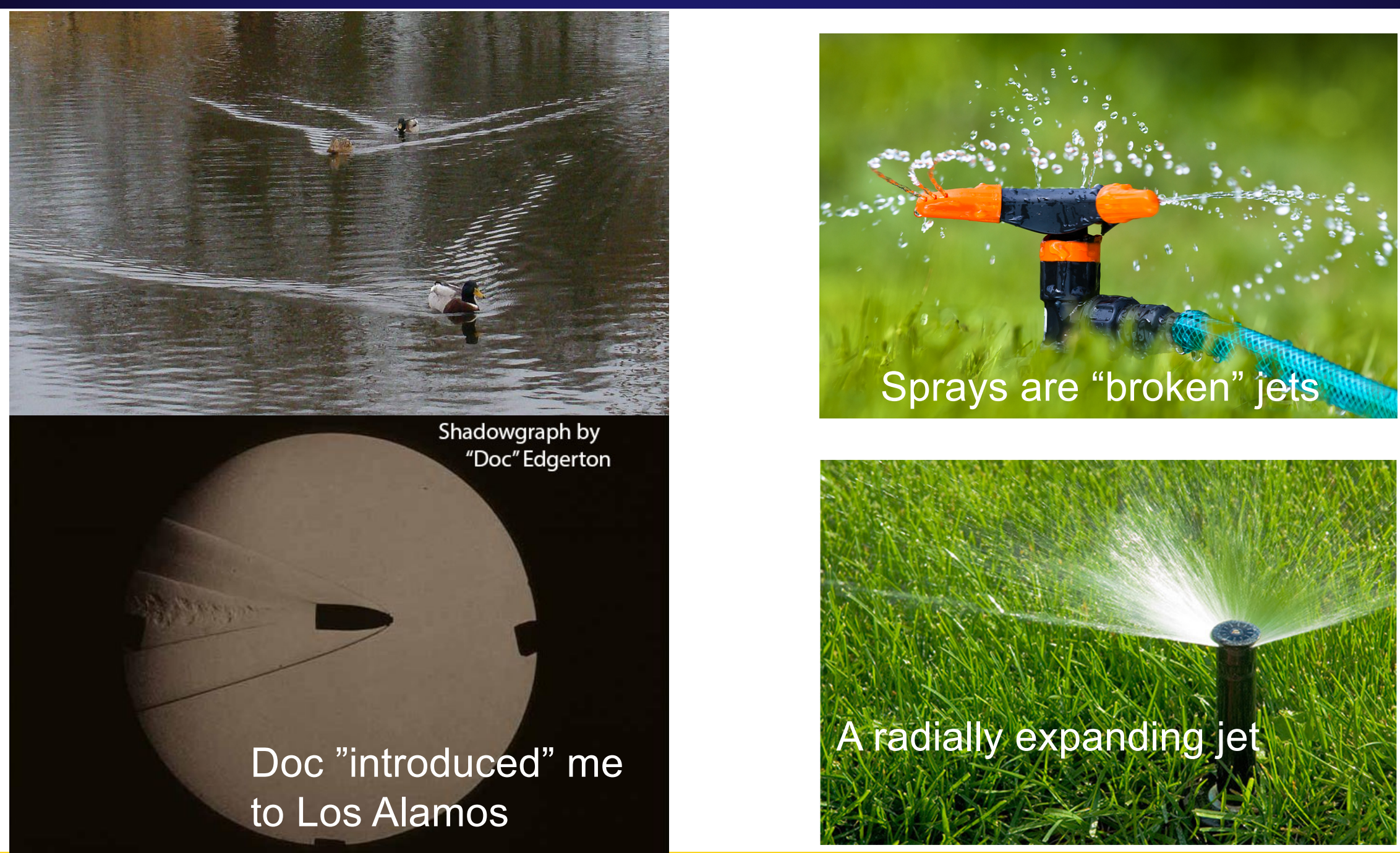

Everyday examples of hydrodynamics are jets and wakes 


\section{Los Alamos Definition of Hydrodynamics}

- Explosives drive metals like they are fluids

- Explosives apply pressures that are far greater than the strength of the metal

- An extremely useful zeroth order approximation

- A shaped charge jet is a common example

Alternating $\mathrm{Cu} \mathrm{Ni}$
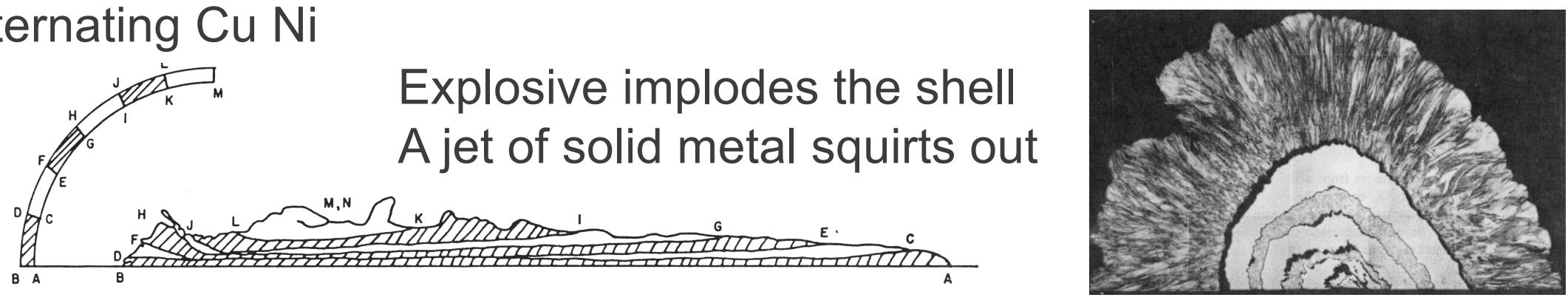

Copper

Explosive pressure overwhelms material strength 


\section{Material Effects are Important in Dynamic Failure, Fracture, Deformation Heating}

- Perturbations to the motion are always present

- Metals are compressible -> Shock waves form

- High pressures can cause various phase transitions

- Impurities in the material

- Our designs have millions of engineering features - nuts, bolts, etc

- Non-uniformity of the drive is always a major factor

- Materials become mechanically unstable and break up clumsily
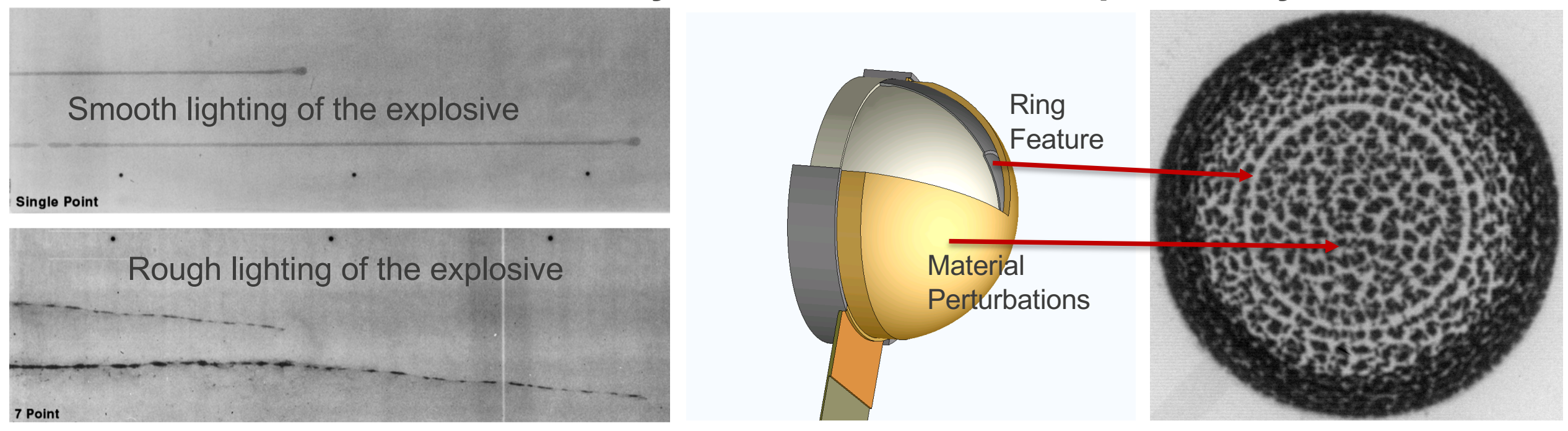

Perturbations Develop Instability: Explosives, Features, Material Effects 


\section{My Work: Incorporation of Explosives, Materials, and other Perturbative Effects into Hydrodynamics}

- An example - use of Photon Doppler Velocimetry for in-surface wave measurements during fracture of a binary alloy

- 3D - 3 probes at a cross point
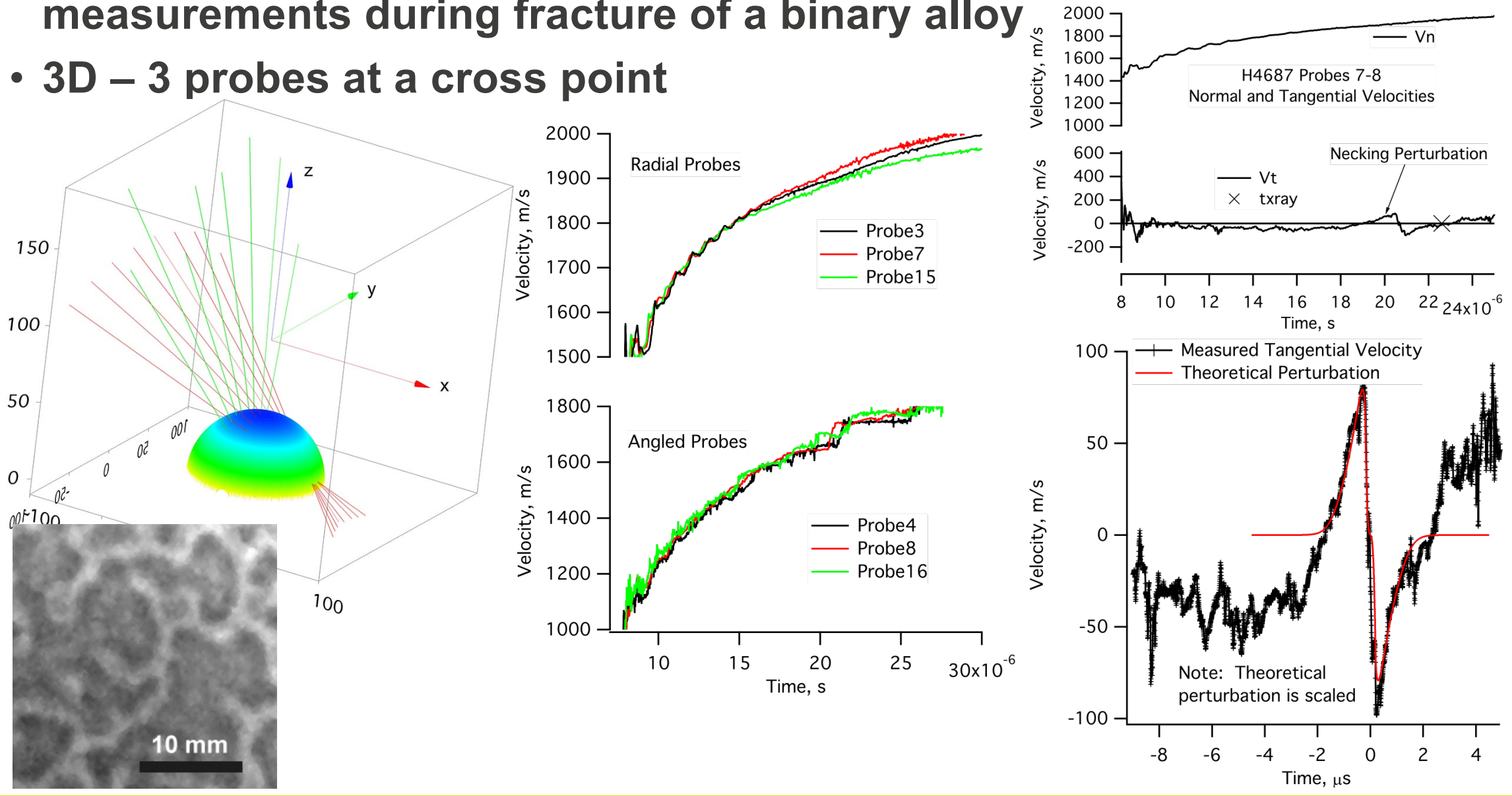

Leads to Physics-Based Material Acceptance Criteria 